\title{
EXPLORING UNPLANNED PREGNANCY AMONGST UNIVERSITY STUDENTS
}

\section{P Naidoo, M Kasiram}

\section{INTRODUCTION}

Unplanned pregnancy poses a multiplicity of problems for students and academic institutions. Using an ecosystemic framework one can uncover the range of costs incurred when a student's academic life is disrupted as a result of an unplanned pregnancy. The academic programme is derailed with serious financial costs incurred by the institution, the family and the individual. Through-put targets of the institution may be affected, leaving a trail of deficits that are difficult to manage, together with a bruised public image that impacts negatively on student intake. At a psycho-social level the individual and family lose standing in the community because of the shame of an unplanned pregnancy and an illegitimate child, or trauma upon learning of a positive HIV diagnosis accompanying pregnancy. These concerns provided the motivation for this study, which was to identify factors that contributed to unplanned pregnancy to reduce its impact and inform proactive planning. No such study had been conducted on the University of KwaZulu-Natal's Westville campus previously. The research was conducted on the Westville Campus of the University of KwaZulu-Natal under the auspices of the Department of Student Counselling from August 2003 to December 2003 to investigate why an increasing number of students were presenting with unplanned pregnancies. This increase is reflected in the statistics below.

Table 1 shows the number of students who approached the University health clinic in respect of family planning (seeking contraception) or unplanned pregnancy. These statistics are reflected until July 2003 only, as the figures from August 2003 to December 2003 were included in this study. There are many more students who do not go to the clinic for services when pregnant, but use other sources of support. However, this number has not been researched. The problem is thus believed to be more widespread than this study reveals.

TABLE 1

FEMALE STUDENTS SEEKING CONTRACEPTION/HELP FOR UNPLANNED PREGNANCY AT THE UNIVERSITY HEALTH CLINIC

\begin{tabular}{|l|c|c|}
\hline \multicolumn{1}{|c|}{ Time period } & $\begin{array}{c}\text { Students seeking } \\
\text { contraception }\end{array}$ & $\begin{array}{c}\text { Unplanned } \\
\text { pregnancies }\end{array}$ \\
\hline 2001 & 400 & 75 \\
\hline 2002 & 224 & 100 \\
\hline 6 month period: Jan-July 2003 & 63 & 46 \\
\hline
\end{tabular}

The statistics above reflect that in 2001 many students sought contraception to prevent pregnancy. This figure decreased in 2002 and for the first six months of 2003 with only 63 students coming to the clinic for contraception. This may be explained by increased condom distribution by the university at residences, all toilets and at the clinic from 2002. Thus, fewer students seem to attend the clinic for contraception because of increased condom availability.

The statistics for unplanned pregnancy show that there was an increase from 2001 to 2002 with figures for the first six months of 2003 being consistent with the previous year. This suggests that students continue to experience unplanned pregnancy during their academic careers. 


\section{RESEARCH STUDY AND THEORETICAL APPROACH}

This exploratory study aimed to investigate the complex set of dynamics contributing to unplanned pregnancy among University students. A small qualitative study using 30 respondents was conducted to collect in-depth information from a sample of students who received services from the student counselling unit at the University. They continued to receive professional services during and after the study. In addition, ethical clearance from the University was secured, with students having provided consent before participating in the study and for publishing of findings.

The theoretical underpinning for the study was an ecosystems paradigm that allowed for understanding the multiplicity of factors that affected unplanned pregnancy. In accord with this approach, recommendations are suggested that have relevance for micro, meso and macro interventions. These are offered in the conclusion of the article.

The students were interviewed using an unstructured interview guideline. Themes explored included details of the pregnancy, risk-taking behaviour, coping and sources of support and knowledge of HIV/AIDS. De Vos (1998) states that the interview is increasingly being used in social science research to provide for systematic data collection that allows the researcher to follow a set structure, while simultaneously allowing flexibility to pursue cues relevant to the study. The absence of prescribed rules created an open field of opportunity in which the interviewer (one of the authors of this article) utilised her skills, intuition and knowledge in identifying the problems and coping of respondents, while offering a supportive service (Kvale, 1996). In social science qualitative research, the distance between the research role and that of service provider may be small, but this does not invalidate the findings, as it is this involvement that inspires seeing the world through the eyes of the respondent, gleaning rich data and "immersion" in the interview as was the case in this study (Babbie \& Mouton, 1998:168).

The data-analysis strategy relevant to this study was inductive reasoning, scrutinising data for establishing relationships or patterns. The Huberman and Miles Approach described in De Vos (1998) was found to suit the purposes of the study. This approach consisted of three linked processes that were employed in data analysis as follows:

- Data reduction from field notes and transcriptions made during the interview;

- Data display where data were organised in a manner to establish links and relationships;

- Drawing conclusions and verification of data.

In conjunction with qualitative data analysis, quantitative analysis was also used where applicable and appropriate. Pie charts were used mainly to display relationships and proportions of parts to the whole. Combining both qualitative and quantitative methods and analyses was useful in this study as it allowed for triangulation in respect of converging results, allowing different facets of data to emerge, initiating fresh ideas from viewing different perspectives and expanding the scope of the study (Creswell, 1994).

A non-probability sampling method was used, i.e. availability sampling. The sample was chosen from the first 30 students who approached the student health clinic from August to December 2003 for services with their pregnancies and who agreed to participate in the study. The small number of subjects chosen was attributable to the data-collection method, time and cost constraints. The sample size was not truly representative of the student population and generalisations cannot be made, though the data gleaned were rich and informative. 


\section{Family response}

In the interviews the researchers explored parental reactions to the pregnancy.

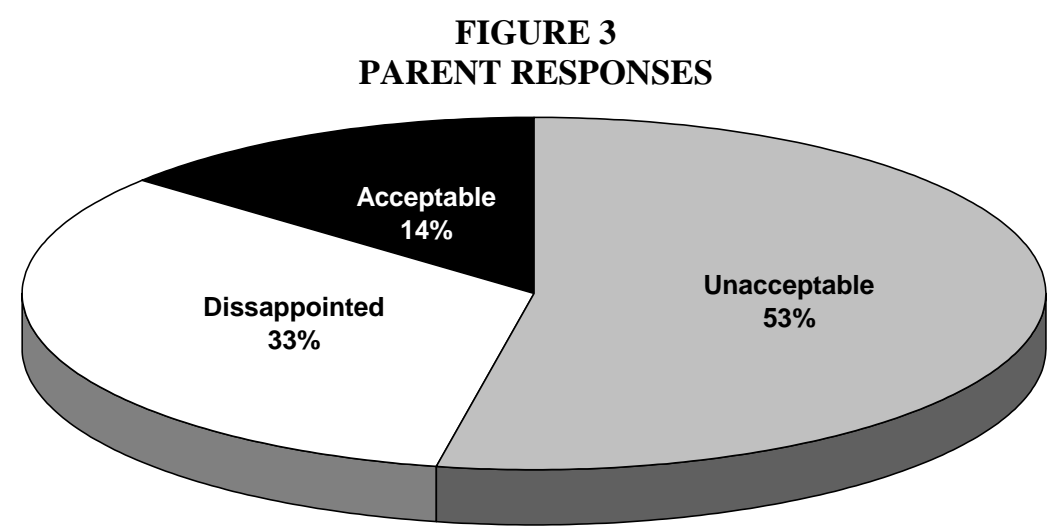

The majority $(\mathrm{N}=26)$ of respondents indicated that their parents would react negatively to news of an unwanted pregnancy, since in African culture it is not considered acceptable for an unmarried female to fall pregnant. This is especially true when studying at a university, often undertaken at great financial costs to the family (Parekh \& De la Ray, 1997). However, most parents had not taught their daughters about sex and the risk of pregnancy. It would appear that parents make financial sacrifices to send their daughters to university, but do not spend time communicating about sex and sexual risk taking. This important discussion/education is left to others to perform. What makes parents believe that their children may not be sexually active, or that they will be correctly educated about contraception? A few parents (14\%) accepted the pregnancy and offered support to their daughters. This acceptance could well derive from their own guilt at inadequate preparation of their daughters to meet the challenges of the outside world as well as their natural parental inclination to care for and support them against all odds. Preston-Whyte and Zondi (1991) too found that, although parents were initially disappointed, they later accepted the child into the family home.

\section{MARITAL STATUS OF PARENTS}

The table below illustrates the marital status of parents of respondents.

TABLE 2

MARITAL STATUS OF PARENTS

\begin{tabular}{|l|c|c|}
\hline Marital Status & Frequency & Percent \\
\hline Respondent with both parents & 17 & $57 \%$ \\
\hline Respondent from single parent home with mother as caregiver & 13 & $43 \%$ \\
\hline Total & 30 & $100 \%$ \\
\hline
\end{tabular}

Respondents were asked about their parents' marital status to ascertain whether parents being married and then having children was important as a family value. Of the 30 respondents interviewed, 17 came from homes where parents were married, while 13 from homes where the mother was the sole parent. Families with both parents married are said to be more stable, serving as role models (Brown, 2002), but this was not the finding in this study. An explanation for students coming mainly from families with both parents married could be that they are in a better 
financial position to send their children to university than a single parent would be. It must also be noted that the difference between the married and single-parent families was not great.

\section{COMMUNICATION ABOUT SEX}

The majority of parents $(\mathrm{N}=18)$ had not talked to their daughters about sex. The remaining 12 respondents had instructed their daughters to abstain from sex, threatening to disown them if they fell pregnant. Fox and Inazu (1980) reported similar findings, namely that few parents gave much direct instruction about sexuality, sexual intercourse or contraception. Respondents had mainly discussed sex with their peers or had learnt about it from the media, both of which were unreliable and sensationalised sex and promiscuity (Parekh \& De la Rey, 1997). The authors endorse the view of Mayekiso and Twaise (1992), who believe that parents should be key informants about sex, a difficulty in traditional homes as sex is not openly discussed (Wilbraham, 2002). The combination of students' new-found freedom and their being largely ignorant about sex produces expensive and embarrassing mistakes. Especially at institutions with students from traditional communities, it is incumbent on service providers and planners to engage creatively with parents and the community to begin to sex talk. A multi-sectoral approach is advocated to bring together multiple role players in correct messaging that is timely and well received.

\section{USE OF CONTRACEPTION}

The table below depicts the responses received on the use of contraception.

TABLE 3

USE OF CONTRACEPTION-CONDOM

\begin{tabular}{|l|c|c|}
\hline Frequency of condom use & Frequency & Percent \\
\hline Every time & 10 & $33 \%$ \\
\hline Occasionally & 11 & $37 \%$ \\
\hline Never & 9 & $30 \%$ \\
\hline Total & 30 & $100 \%$ \\
\hline
\end{tabular}

Thirty-three percent $(\mathrm{N}=10)$ of the respondents used contraception (a condom) during every sexual encounter. Thirty-seven percent $(\mathrm{N}=11)$ used a condom occasionally and $30 \%(\mathrm{~N}=9)$ never used any contraception at all. Of the 33\% who used a condom every time, 39\% indicated that the condom burst during intercourse. The remaining $61 \%$ had no idea how they fell pregnant. The statistic of $33 \%$ falling pregnant despite condom use is high and not in keeping with the low failure rate (12-16\%) discussed by Sulak (2002). It is possible that respondents in this study were not using the condom correctly, pointing to poor sex education and incorrect contraceptive use.

Only $37 \%$ used a condom occasionally and $30 \%$ used no contraception at all. Some reasons for erratic use were: "My boyfriend forgot to buy/did not feel like using the condom", and "He refused to listen to me when I told him that we did not have a condom and could not have sex".

According to Coombe (2000), reasons for agreeing to unsafe sex included fear of abandonment or violence. Browne and Minichiello (1994) state that men are seen as the aggressors and feel entitled to pressure women into sex. From the responses it was apparent that neither partner had grasped the significance of regular and reliable contraception and that the women could not persuade their partners to practise safe sex. Females believe they are powerless and that males should make decisions about condom use, since they have to use it. Irregular use of a condom, according to De Visser and Le Roux (1996), is also due to unmarried women having sporadic sexual encounters, an 
explanation that is applicable in this study, since it was apparent from the interviews that respondents did not always predict that sexual intercourse would occur. However, even when sex did occur, they did not practise safe sex on subsequent sexual encounters.

Reasons for not using contraception were: "having sex for the first time", "using contraception but stopped when the relationship broke up and did not plan to have sex in new relationship", "having sex for a long time without contraception and therefore did not think I could fall pregnant", and "I trust my boyfriend and we have been careful".

These comments demonstrate a poor understanding of reproduction and that contraception was the partner's ultimate responsibility. For the female this places control outside of oneself (Gueye, Castle \& Konate, 2001; Perkel \& Strebel, 1991). Gueye et al. (2001) point out that locus of control is closely related to self-esteem and confidence. Respondents in the study lacked confidence and had low self-esteem; this was expressed in their fear of losing partners, not informing partners of the pregnancy in some instances and not wanting to dominate in the relationship. Assuming responsibility for the pregnancy seemed a small price to pay for a "secure" relationship with partners, pointing to a need for the empowerment of women to build their confidence and help them take charge of their sexual health and relationships.

Most of the knowledge on contraception was obtained from awareness campaigns at school, university and peers. Only two respondents' parents discussed contraception. Parents basically instructed them to abstain from sex. There was clearly no meaningful exchange and communication about sex, a finding that has already been discussed.

Respondents who used contraception referred only to condom use, although they knew of other methods of contraception such as the injection and pill. A few were not aware that contraception was available at the University health clinic free of charge, while others had incorrect information on the use of the pill, e.g. using the pill only before sex.

Respondents offered the following reasons for not opting to use either oral contraceptives or the injection: "my body will turn to jelly and I would become unattractive", "people will see you putting on weight and know that you are taking contraception and say that you are sleeping around", "if I take the pill my mother will find it and scold me for having sex", "it made me feel sick", "I did not get time to take the injection".

Mfono (1998) cites similar reasons for poor use of the contraceptive pill. Thus together with lack of knowledge regarding proper use of the different contraceptive methods, other reasons for not using contraception were implied acceptance that sex was going to be regular, and concern over body image. When these reasons are set against a backdrop of pregnancy, a ruined academic career and having HIV/AIDS, their inappropriateness and irrelevance become abundantly clear.

Most respondents had knowledge of the emergency contraception (EC) or morning after pill. Students who were aware that the condom had burst used the EC but still fell pregnant. The EC has been documented as having very low failure rates (Barret \& Harper, 2000), yet in this study it did not prevent the pregnancy. It could be that respondents fell into the low failure rate category or, more plausibly, that they were again using the method incorrectly. The trend of incorrect contraceptive use and lack of understanding of the reproductive process is noted. This finding is alarming considering the context, namely that respondents were educated university students who have access to knowledge.

The female condom is one of the newer contraceptive devices on the market. None of the respondents used the female condom, although they had heard of it or seen it demonstrated at the University. The reason for this could be cultural, where females from traditional African 
communities (respondents were mainly in this category) are uncomfortable about touching their private parts. Also the cost of the female condom puts it beyond the reach of most students (UN Integrated Regional Information Networks, 2003). The female condom provides an alternative to protect women against unwanted pregnancy and HIV/AIDS, but is not being fully used, suggesting a need to market the device more aggressively. Furthermore, the device needs to be regarded as a tool to empower women to take charge of their sexuality, since its use lies with the female and she has the opportunity to reclaim locus of control in the relationship.

\section{Partner response}

FIGURE 4

PARTNERS' REACTION TO PREGNANCY

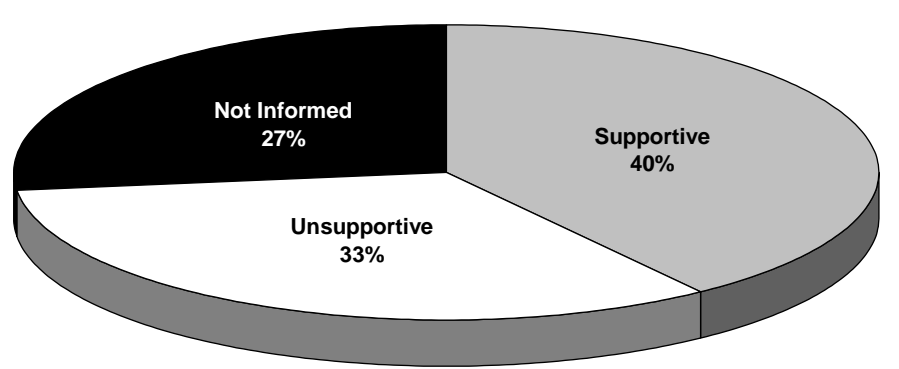

Although most partners were "supportive", half of them in this category suggested termination of the pregnancy, while the rest offered to assist the child and mother in different ways. This finding was confusing as support generally surpasses advice only. Interviews shed some light on this, where partners appeared willing to offer support provided that there was financial security and family assistance for the pregnancy. Moore and Rosenthal (1993) too note that abortion should not be seen as indicating a lack of interest or support for the pregnancy, but rather as helplessness to provide for the child.

During interviews respondents expressed disappointment when questioned about marriage as none of their partners had offered marriage, indicating that the relationships may not have been intended to be long term. Thus termination was an easy option within a relationship that was not intended to end in marriage. This finding points to a lack of communication - males appear to have sexual relationships without expectations of commitment, while females appear to want commitment without clearly expressing this in the relationship. This again suggests the powerlessness of the female in the relationship and that the female goes to great lengths to keep her partner satisfied.

Thirty-three percent of the respondents indicated that their partners were unsupportive. Partners became upset, blamed the female for the pregnancy, denied being the father and accused the respondent of unfaithfulness. These responses further stress females, as they now have to be burdened with both an unplanned pregnancy and friction in the relationship. De Visser and Le Roux (1996) reported similar negative responses from males when their partners fell pregnant. Moore and Rosenthal's (1993) explanation for these responses is conditioning in retaining a "macho" image, and of having numerous sexual exploits and not being concerned about their consequences. Maharaj (2001) expressed this quite boldly in asserting that men have been viewed as uninvolved in fertility except for providing the sperm. This is aggravated by most familyplanning programmes being focused on women rather than men, and needs remedying. Clearly 
men need to be educated about responsible sex, accepting the consequences of unprotected sex and what constitutes being a "real man".

Twenty-seven percent $(\mathrm{N}=8)$ of the respondents opted not to inform their partners of the pregnancy. Reasons for this response were: the partner would insist on continuing with the pregnancy when they themselves wanted a termination; preserving the relationship without undue stresses such as an unplanned pregnancy; and not risking being judged as immoral if the pregnancy is terminated. Poor communication and an image that was different to the one being lived once again indicate helplessness and powerlessness. It is necessary for female empowerment to become a goal that needs attention well before sexual intercourse is contemplated.

\section{Respondents' reactions}

FIGURE 5

\section{DECISION ABOUT PREGNANCY}

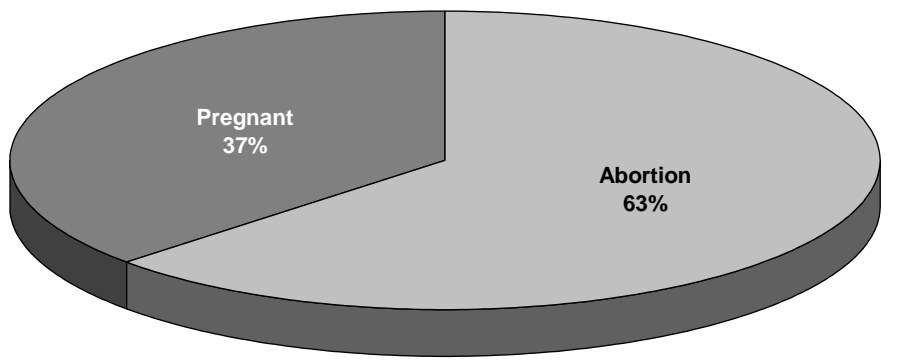

More respondents opted to abort than continue with the pregnancy. Of the $11(37 \%)$ respondents who decided to continue, three continued simply because they were too advanced to terminate. The rest $(\mathrm{N}=8)$ continued because of religious beliefs and fear of abortion. Thus it appears that termination was the simplest option, but it came at a price. The interviewees discussed the stress and grief accompanying decisions, all of which negatively affected their academic work. Stress was compounded by the burden of not being able to share information with others. Regardless of the choices made, all students in the study received ongoing professional assistance. As the number of students requiring the service increases, but without a corresponding increase in professional staff, it is recommended that peer educators be used to offer much-needed support and referral. This will have the added benefit of peer exchange and a participatory focus.

\section{PREGNANCY AND HIV/AIDS}

The following data regarding sexual risk-taking and HIV/AIDS were obtained:

TABLE 4

SEXUAL RISK-TAKING AND HIV/AIDS

\begin{tabular}{|l|c|}
\hline Response & Percentage \\
\hline Unconcerned about HIV/AIDS, no protection & $4 \%$ \\
\hline Concerned, but did not use protection & $33 \%$ \\
\hline Trusted partners, so did not use protection & $17 \%$ \\
\hline Had AIDS tests, so did not use protection & $13 \%$ \\
\hline Concerned and used protection & $33 \%$ \\
\hline
\end{tabular}


A large majority of $67 \%$ did not use protection, a concern that points to students opening themselves to HIV infection and unplanned pregnancy. Some respondents had concerns about HIV, but lacked skills in enforcing the use of a condom or refusing sex. Such risk-taking threatens the future psycho-social and academic lives of male and female students, and needs addressing. Rutenberg, Kaufman, MacIntyre, Brown and Karim (2002) reported similar risk-taking, where knowledge of HIV did not prevent students from having unprotected sex, indicating a widespread trend in sexual risk-taking and suggesting a need for macrosystemic responses to reduce its impact.

\section{RESOURCES}

Respondents indicated that they would discourage other students from falling pregnant while at university, as it is very stressful. The resources used by respondents were the University health clinic and student counselling services. Students opting for abortions were referred either to provincial hospitals or private clinics. Students did not indicate that they required additional support and resources, despite confiding to being stressed and even traumatised. The explanation may be that students are afraid to share the information with others for fear of being judged; this points to attempts to redress the problem needing to recognise the intensity and far-reaching consequences of such fear. De Visser and Le Roux (1996) suggest that provision of childcare facilities should receive the highest priority, a point not recommended by respondents, to enable them to undertake academic and parental responsibilities simultaneously. It was almost as though students wished to block out knowledge of the pregnancy and refused to consider long-term arrangements in the best interests of their children and themselves. Again fear and powerlessness to take charge of their future were noted.

\section{LIMITATIONS AND FURTHER RESEARCH}

Findings of this study need to be considered against the backdrop of the limitations indicated below.

- The sample size limited generalisability, but this did not invalidate the research as it was essentially exploratory in nature. A similar regional and/or national study with a larger sample would increase generalisability.

- Some respondents were initially vague because of the emotional shock upon receiving the results of their pregnancy test. Much time-consuming probing was necessary to obtain data, with the possibility that sufficient time may not have been spent with all respondents to glean information on the full problem-saturated story.

- Responses of males were obtained via their female partners. These responses may have been biased, suggesting a need to use males as the primary sample in further research.

- Respondents may have changed their minds about the pregnancy after the interview and this information is absent in the study, suggesting a need for future research to have a longitudinal research focus.

- Findings were that a condom failed to prevent pregnancy. This problem area could be the focus of a future study. 


\section{CONCLUSIONS AND RECOMMENDATIONS}

- University students were found to experience a newly acquired freedom away from home, resulting in sexual intimacy when this was not always anticipated. In addition, students were found to possess limited reliable information on sex, reproduction, contraception and negotiating contraceptive use in relationships, causing stress when pregnancy resulted. Educative goals were put on hold, as parenting was demanded or when grieving over losses through abortion took precedence. Sexual risk-taking along with limited sex education came at a high price.

- Parents were not communicating to their youngsters about sex or were simply warning them not to fall pregnant. The reluctance to talk about sex is well documented and entrenched in many communities. Creative ways to break the silence around sex, pregnancy and HIV/AIDS could be accomplished through a multiplicity of ways, amongst these "narrative theatre" (story-telling by the people for the people) that would speak to people from their frame of reference to dispel myths and relay important education and understanding around the empowerment of women, safe sex and sexual health. When community members are taught to develop a consciousness of community issues, they re-affirm their collective strength (Nair 2004) and may thus be enabled to better address the problem of unwanted pregnancies, unwanted children and exposure to HIV/AIDS.

- Women in the study were found to be naïve, overly trusting, fearful, disempowered and silent in practising safer sex or confiding to their partners about their pregnancies. Women need to re-claim locus of control in relationships. One way of accomplishing this goal would be through affirming women through national campaigns, highlighted with the help of mass media such as "Take a girl child to work" and "Women's Day". At an exosystemic and microsystemic level at the University, there could be participatory groups formed by the student counselling unit to negotiate contraceptive use in the relationship and generally solve problems related to either the pregnancy or sexual health concerns (Gage, 1997). These could be initiated with the help of coordinators at the hostel, where a climate of care and empathy prevails. Students would then be instrumental in helping each other and be viewed as "kinship carers" and therapeutic agents (Petty, 2004).

- Support groups using kinship carers could be established by the Department of Student Counselling to assist pregnant females and their partners to cope with the pregnancy while at University. Long-term planning was lacking in regard to the future of the relationship as well as to the newly acquired roles of students as parents. Where decisions were made to terminate the pregnancy, students could be supported through this difficult phase.

- The Department of Student Counselling, together with the University health clinic, could embark on a campaign to encourage more use of different contraceptives correctly. Some methods were not being fully used because of their perceived side effects, so it is necessary to explore how body image and health may still be ensured during contraceptive use. Some of these methods could be promoted to help females take responsibility for their own sexual health, as the study revealed that they had handed this over to their partners. Campaigns should continue throughout the year, using edutainment (education and entertainment) and employing creative artists since saturation is easily reached when similar messages are repeated in mundane ways.

- Therapeutic and educative programmes should target first-year students during the orientation period and continue throughout the year to keep the message alive, as the study indicated that first-year students experienced unplanned pregnancies the most. 
- Programmes on contraception should also target males as indirect stigmatisation occurs when the focus is primarily female. Males in the study were found to have a distorted "macho" image that correlated with having numerous sexual experiences. Peer educators using participatory approaches could be used to provide men with an opportunity to re-shape attitudes about what constitutes being a "real man" and assuming responsibility for actions from a human rights and gender equality perspective (The World Population Day Essay Competition, 2000).

- Cultural and religious leaders in the community should play a more active part in highlighting the roles and responsibilities of males in preventing unwanted pregnancies and the spread of HIV/AIDS. They could also provide support for females to assert their needs, thereby sending out the message that it is okay to refuse sex or to insist on protection. Institutionalised support for such messages could spear-head change in developing "awareness of systems of privilege and oppression that define equity and justice" (McDowell, Fans, Brownlee, Young \& Khanna, 2002:180).

- Schools should educate learners about sexuality, contraception and female empowerment. School counsellors and/or social workers need to be employed to coordinate educative campaigns and supportive services in this regard.

- The University of KwaZulu-Natal, Westville Campus has no policy to deal with pregnancy as a medical emergency, especially pre-term birth. A birth at the residence can be traumatic, not only for the mother but also for her room-mates. Policy could include a clause requesting the mother to go home a month prior to her due date, and this time period could be a condoned period of absence. Policy should also guide students on available resources and services at the University.

\section{REFERENCES}

BABBIE, E. \& MOUTON, J. 1998. The practice of social research. New York: Oxford University Press.

BARRET, G. \& HARPER, R. 2000. Health professionals' attitude to the deregulation of emergency contraception. Sociology of Health and Illness, 22(2):197-216.

BROWN, R.T. 2002. Adolescent pregnancy. Available: www.cool.nurse.com/pregnancy2.htm

BROWNE, J. \& MINICHIELLO, V. 1994. The condom: Why more people don't put it on. Sociology of Heath and Illness, 16(2):229-251.

COOMBE, C. Cultural beliefs and customs. Available: www.edc.org/GLG/hivimpact/hypermail/0184.htm

CRESWELL, J.W. 1994. Research designs - qualitative and quantitative approaches. London: Sage Publications.

DE BRYN, L. \& JOUBERT, G. 2002. The perceptions of female students regarding STDs and HIV. South African Medical Journal, 92(3):202-203.

DE VISSER, J. \& LE ROUX, T. 1996. The experience of teenage pregnancy in Knoppieslaagte. South African Journal of Sociology, 27(3):98-106.

DE VOS, A.S. 1998. Research at grassroots. Pretoria: J.L. Schaik. 
FOX, G.L. \& INAZU, J.K. 1980. Patterns and outcomes of mother-daughter communication about sexuality. Journal of Social Issues, 36(1):7-29.

GAGE, A. 1997. Female empowerment and adolescent behaviour. Available: www.qweb.kvinnoforum.se/papers/Gage.htm

GARENNE, M., TOLLMAN, S. \& KATHLEEN, K. 2000. Premarital fertility in rural South Africa: A challenge to existing population policy. Studies in Family Planning, 31(1):47-54.

GUEYE, M., CASTLE, S. \& KONATE, M.K. 2001. Timing of first intercourse among Malian Adolescents: Implications for contraceptive use. International Family Planning Perspectives, 27(2):56-62.

KVALE, S. 1996. Interviews: An introduction to qualitative research interviewing. Thousand Oaks, California: Sage Publications Inc.

MAHARAJ, P. 2001. Male attitudes to family planning in the era of HIV/AIDS: Evidence from KwaZulu-Natal, South Africa. Journal of Southern African Studies, 27(2):245-257.

MAYEKISO, T.V. \& TWAISE, N. 1992. Assessment of parental involvement in imparting sexual knowledge to adolescents. South African Journal of Psychology, 23(1):21-23.

MCDOWELl, T., FANG, S.-R., BROWNLEE, K., YOUNG, C.G. \& KHANNA, A. 2002. Transforming and MFT Program: A model for enhancing diversity. Journal of Marital and Family Therapy, 28(2):179-191.

MFONO, Z. 1998. Teenage contraceptive needs in urban South Africa: A case study. International Family Planning Perspectives, 24(4):180-183.

MOORE, S. \& ROSENTHAL, D. 1993. Sexuality in adolescence. London: Routledge.

NAIR, Y. 2004. Information, self-empowerment or collective action? Working with youth to prevent HIV/AIDS. Paper presentation at the $9^{\text {th }}$ SAAMFT International Conference, Durban.

PAREKH, A. \& DE LA REY, C. 1997. Intragroup accounts of teenage motherhood: A community based psychological perspective. South African Journal of Psychology, 27(4):223-230.

PERKEL, A.K. \& STREBEL, A. 1991. The psychology of Aids transmission- issues for intervention. South African Journal of Psychology, 21(3):148-151.

PETTY, A. 2004. A developmental approach to reaching traumatized children in kinship care placements in the Umlazi Area. Paper presentation at the $9^{\text {th }}$ SAAMFT International Conference, Durban.

PRESTON-WHYTE, E. \& ZONDI, M. 1991. Adolescent sexuality and its implication for teenage pregnancy and aids. South African Journal of Continuing Medical Education, 9(11):13891394.

RUBIN, A. \& BABBIE, E. 1997. Research methods of social work ( $3^{\text {rd }}$ ed). USA: Brookes/Cole Publishing Co.

RUTENBERG, N., KAUFMAN, C.E., MacINTYRE, K., BROWN, L. \& KARIM, A. 2002. "Pregnant or positive: Adolescent childbearing and HIV risk in South Africa. Available: www.popcouncil.org/pdfs/wp/162.pdfs/wp162.pdf

SULAK, P. 2002. Adolescent sexual health: Providing factual information. Available: www.worthwait.org/healthcare/articles.html 
VILLARREAL, M. 1998. Adolescent fertility: Socio-cultural issues. Available: www.fao.org/WAICENT/FAOINFO/SUSTDEV/Wpdirect/Wpan0024.htm

WILBRAHAM, L. 2002. Parents talking with youth about sex and aids: Some problems with health education materials. Aids Bulletin, 11(4):1-5.

\section{Unauthored websites}

Perceptions and thoughts on teenage pregnancy as reflected by some participants in: The World Population Day Essay Competition. 2000.

www.population.pwv.gov.za/Documents/adoperceptions.htm

UN Integrated Regional Information Networks. 2003. "Traditional Culture Spreading HIV/Aids". www.aegis.com/news/irin/2003/IR030322.htm

Ms P Naidoo, student counsellor at the Department of Student Counselling on the Westville Campus of the University of KwaZulu-Natal and Prof M Kasiram, Professor in the School of Social Work and Community Development, University of KwaZulu-Natal, Durban, South Africa. 
